\title{
A66 S100A8/A9 IN BLEOMYCIN-INDUCED SKIN FIBROSIS
}

Andréasson $K_{1}^{1}$ Gustafsson $R_{1}{ }^{2}$ Ivars $F_{1}{ }^{2}$ Roth $J_{1}{ }^{3}$ Vogl $T_{1}{ }^{3}$ Hesselstrand $R_{1}{ }^{1}$ Heinegård D, ${ }^{1}$ Saxne $T^{1}{ }^{1}$ Department of Clinical Sciences, Lund University, Lund, Sweden; ${ }^{2}$ Departement of Experimental Medical Science, Lund University, Lund, Sweden; Institute of Immunology, University of Münster, Münster, Germany

\subsection{6/ard.2010.149104.10}

Background and objectives Systemic sclerosis is a heterogeneous disease characterised both by inflammation and fibrosis. TLR4-dependent signalling has been proposed to play a significant role in the connection between inflammation and fibrosis in SSc. We have previously found increased levels of the TLR4-agonist S100A8/A9 in both serum and faeces of patients with SSc. In this study, we examined the role of S100A8/A9 in the pathogenesis of inflammation induced skin fibrosis in the bleomycin mouse model.

Materials and methods S100A9-/ mice were kept on a C57 $\mathrm{Bl} / 6$ background. These mice lack biologically active S100A8/ A9 protein complex. Wild type (WT) littermates were used as controls. In total, 40 age matched female mice were used. Skin fibrosis was induced by 12 subcutaneous injections of bleomycin over a 4 week period. Dermal skin thickness was evaluated by light microscopy and skin collagen content by measurement of hydroxyproline. Skin concentration of water and fat was evaluated after freeze-drying and fat extraction of skin biopsies with acetone respectively. Punch biopsies were taken for later mRNA quantification by rtPCR and for electron microscopy.

Results Skin thickness increased to a similar extent in WT and S100A $9 \%$ mice compared to saline injected animals after bleomycin treatment $(262 \pm 11 \mu \mathrm{m}$ vs $263 \pm 12 \mu \mathrm{m})$. The amount of collagen also increased to the same level in WT and S100A9 $\%$ mice $\left(53 \pm 1.6\right.$ vs $\left.53 \pm 0.9 \mu \mathrm{g} / \mathrm{mm}^{2}\right)$. Compared to saline injected control mice, bleomycin treatment resulted in an increase in skin water content in WT $(70 \pm 0.6$ vs $65 \pm 1.3$ $\% ; p<0.001)$ but not in the S100A9 $\%$ mice ( $68 \pm 1.3$ vs $68 \pm 0.5$ $\%)$. Bleomycin treatment caused a more pronounced reduction of dry skin fat content in WT (41 \pm 2.6 in saline vs $17 \pm 1.6 \%$ in bleomycin treated mice; $\mathrm{p}<0.001)$ than in S100A9-/- mice $(36 \pm 1.4$ vs $23 \pm 2.2 \% ; p=0.002)$.

Conclusion S100A9 deficiency does not protect mice from bleomycin induced skin fibrosis. S100A9 deficiency seems to attenuate inflammatory changes of skin composition in the bleomycin mouse model of skin fibrosis. 